\title{
Exploración Botánica de la Barranca de Tolantongo,
}

\author{
por el Dr. Ladislao Paray.
}

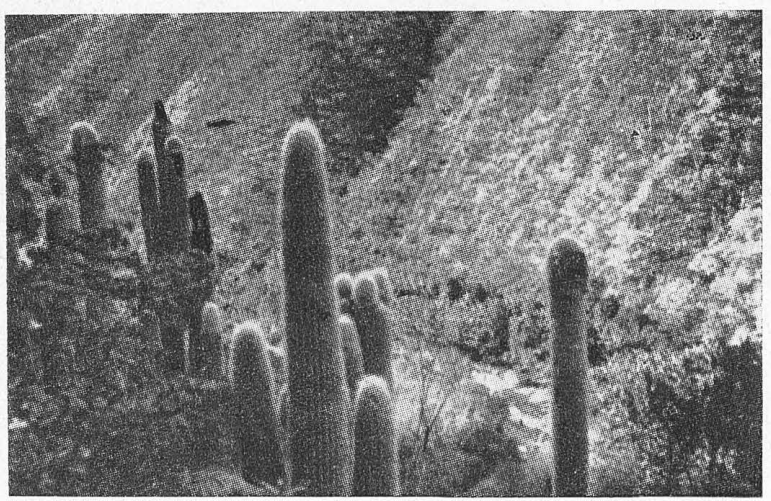

La Barranca de Tolantongo se encuentra a unos $50 \mathrm{Km}$. al Noreste de Ixmiquilpan, Hgo. Desde Ixmiquilpan conduce un camino de herradura transitable para automóviles al pequeño poblado minero de Cardonal y de allí a una ranchería llamada El Manchado. Llegando en automóvil a este punto, empieza una abrupta y accidentada sierra donde la única manera de transitar es a pie o a caballo. Dediqué los días 19,20, 21 y 22 de noviembre del año en curso (1942) para explorar esta sierra y especialmente la Barranca de Tolantongo.

Se inicia la marcha por la falda de altos cerros cuyas cimas están cubiertas de bosques bastante tupidos de diversas especies de Juniperus y Cupressus. Las laderas se cubren de escasa vegetación compuesta sobre todo de gran variedad de Cactáceas.

Después de unas dos horas de marcha incesante por las laderas se llega al borde de una barranca de gigantescas proporciones. El 


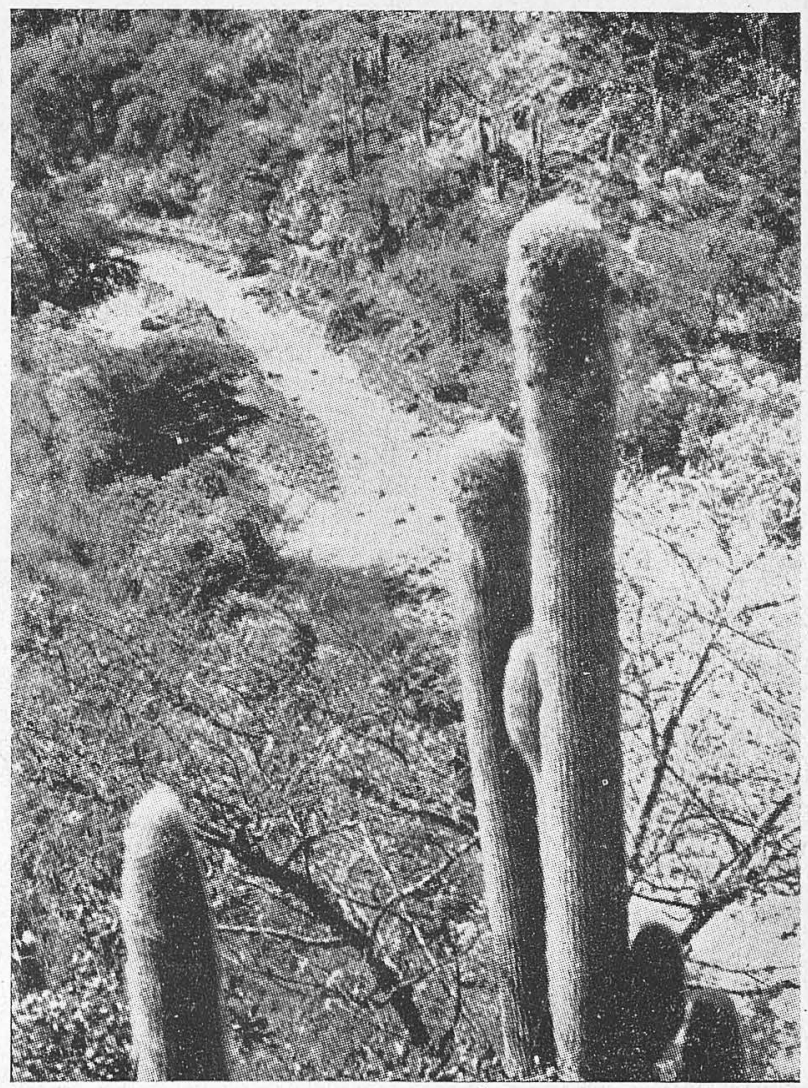

espectáculo que se presenta al caminante es realmente grandioso: una profundísima y angosta barranca rodeada de montañas casi perpendiculares. La profundidad del fondo del abismo calculándola moderadamente es de unos $1000 \mathrm{~m}$. De modo que se trata de una hendedura en medio de las montañas de estupendas dimensiones. Iniciamos el descenso por una escarpada pared casi vertical, cuya cima está a más o menos $2000 \mathrm{~m}$. sobre el nivel del mar y tenemos que bajar a una profundidad de unos 800 o $600 \mathrm{~m}$. Empleamos cuatro horas de penosa marcha en el descenso por la formidable pared. Desde aquí observo con detenimiento las especies vegetales.

La vegetación es de tipo xerofítico, dominando las Cactáceas. Los gigantescos Cephalocereus senilis, o "viejitos", dan un carácter especial al paisaje. Alcanzan estos monumentos vegetales hasta 15 o $20 \mathrm{~m}$. de altura. La vegetación arbórea se caracteriza por un 
arbolito de unos 5-7 m. que tiene el aspecto del olivo. En efecto. el envés de las hojas imita el de las hojas del olivo siendo casi blanco, en cambio el limbo es más verde que el de las hojas del olivo. El porte del árbol aumenta la impresión de encontrarse en frente de un olivo. Los nativos de la región dan el nombre de olivo a este curioso arbolito. Desgraciadamente no encontré flores ni frutos del mencionado árbol, así que su clasificación es imposible.

Al lado del olivo crece en gran abundancia la Ipomoea probablemente Wolcotiana. Encuentro dos especies de Pterostemon, uno es Pterostemon mexicanum y el otro desconocido, tal vez una nueva especie. Este arbolito alcanza unos $4 \mathrm{~m}$. de altura. Con su porte elegante y sus flores blanco rosadas es uno de los árboles y arbustos más bellos de la región. Para este género se creó una familia especial llamada Pterostemonáceas muy cercana a las Saxifragáceas. Abundan los huizaches o acacias y la Neopringlea integrifolia. Más abajo aparece el arbolito Krameria cytisioides, de agradable aspecto. Alcanza hasta $5 \mathrm{~m}$. de altura. Sus flores son moradas y sus hojas trifoliadas. Esta especie es la única Krameria que tiene tres foliolos.

Entre los arbustos, indudablemente el más elegante es la Gardochia mexicana. Sus flores son vistosas, de color naranjado rojo, de unos $31 / 2 \mathrm{~cm}$. de largo. Este género es muy cercano al Clinopodium o Satureja. Sus hojas exhalan un aroma muy parecido al del Clinopodium o Calamintha. Abunda el Croton ciliato-glandulosus, pero una Dalea arbustiva caracteriza más que nada la región. Encontré esta Dalea en plena floración. Hay dos variedades; una con flores rosadas y otra con moradas. Hay gran cantidad de un Eupatorium arbustivo y de un bellísimo Ageratum. La Salvia Grahamii es también arbustiva, con unas flores enormes de unos $2 \frac{1}{2} \mathrm{~cm}$. de largo; abunda también el Trixis longifolia.

En cuanto a la vegetación herbácea, hay gran cantidad de Stachytarpheta, una Ruellia probablemente pilosa; con flores de gran tamaño, de unos $6 \mathrm{~cm}$. de diámetro. Encontré Calophanes y Tetramerium con grandes flores blancas, de unos $3 \mathrm{~cm}$. de largo. Abunda el Hibanthus o Allionia trichodonta. Encontré dos especies de Perezia, Mentzelia grandiflora, Loeselia coerulea, y una Bouvardia afine a la ternifolia.

En el fondo de la barranca la vegetación cambia completamente y se vuelve semi-xerofítica, algo higrófila Las condiciones climatéricas son distintas aquí de las de las laderas de la montaña. El fondo, como mencioné, tendrá de unos 600 a $800 \mathrm{~m}$. sobre el nivel del mar. El lugar está protegido por ambos lados de inmensas murallas verticales de las montañas que lo rodean. Además, corre un río llamado Río Blanco en el fondo de la barranca. Este río nace allí mismo en el extremo de la barranca, de manantiales de agua caliente de unos 40 grados de temperatura. De modo que las aguas del río son calientes en una longitud de más de 


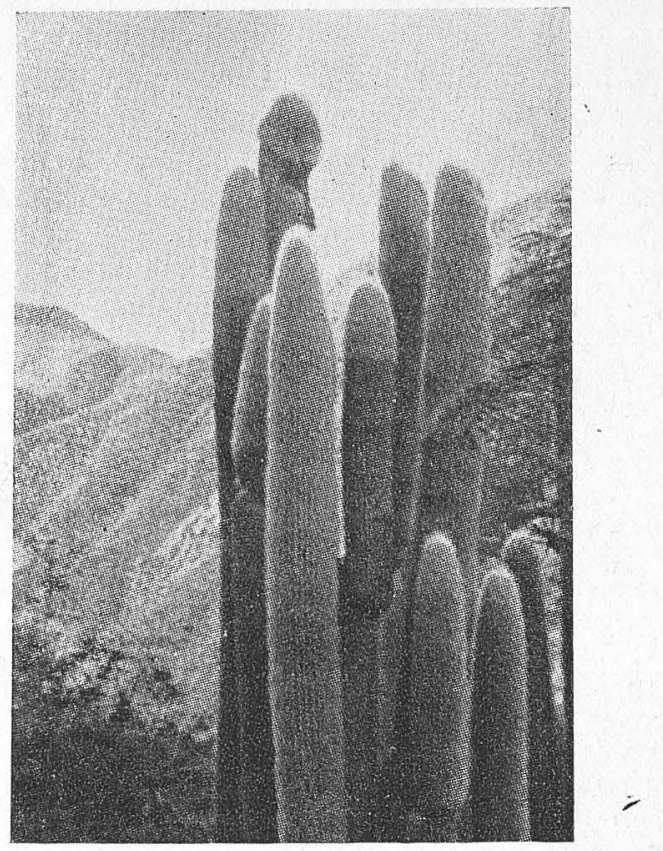

$10 \mathrm{Km}$. Yo recorrí más o menos $15 \mathrm{Km}$. de dicha barranca. Cerca del manantial el río es tan caliente, que en la mañana y en las horas vespertinas, densas columnas de vapor cubren la superficie y envuelven en un manto caliente la vegetación ribereña.

La vegetación arbórea se caracteriza por el anacahuite (Cordia Boissieri), arbolito que alcanza hasta $6 \mathrm{~m}$. de altura. Abundan las Morkillia mexicana de la familia de las Zigofiláceas. Este árbol es sumamence pintoresco, estando cubierto de grandes flores moradas cuyos pétalos miden hasta $3 \mathrm{~cm}$. de largo. El vulgo lo designa con el nombre de "Manto de Coyote." Cerca de los manantiales crecen los Citharexylum tetramerium de la familia de las Verbenáceas, la Chiococca alba y la Vallesia glabra. Esta última se conoce entre los nativos con el nombre de "cristalillo." También encontré muchas leguminosas pero sin flores y sin frutos. Desde luego no faltan el huizache y el mezquite.

Crece allí una enorme Verbesina o género cercano a éste, que es arborescente en este lugar. Entre las Burseráceas consignaré la chaca, probablemente la Bursera simaruba. No falta la Tournefortia, árbol que alcanza hasta $6 \mathrm{~m}$. de altura.

La vegetación arbustiva se caracteriza por la gran cantidad de una Jatropha sumamente venenosa. Como dato curioso, mencionaré que esta Jatropha crece con predilección en la sombra de 
otros árboles y arbustos inofensivos. Se podría decir con una poca de imaginación que se trata de guardianes que cuidan celosamente a la especie vegetal de cuyo cuidado y defensa se encargan. Más de una vez me espiné en ellas tratando de cortar ramas de diferentes plantas.

Considero como el más notable hallazgo en la Barranca de Tolantongo el de una bellísima y vistosa Acantácea. Esta es un arbusto de unos 2 a 3 metros de altura densamente piloso. Las inflorescencias son racimos largos que alcanzan hasta $20-25 \mathrm{~cm}$. La corola es amarilla algo rerdosa, bilabiada, siendo el labio superior una especie de casco mientras el labio inferior tiene tres lóbulos, cada uno de $1 \mathrm{~cm}$. de largo. Tiene dos estambres y cada estambre dos anteras. El estigma es curvado y ligeramente bífido. Los sépalos son petaloides y foliáceos, de color morado; miden $11 / 2 \mathrm{~cm}$. Las dos brácteas son también coloridas. Las hojas son algo aovadas, abajo más redondeadas, de unos $6-8 \mathrm{~cm}$. de largo. Las flores exhalan un aroma delicado sumamente agradable, parecido al aroma de la Ruellia Bourgaei y al del Louteridium.

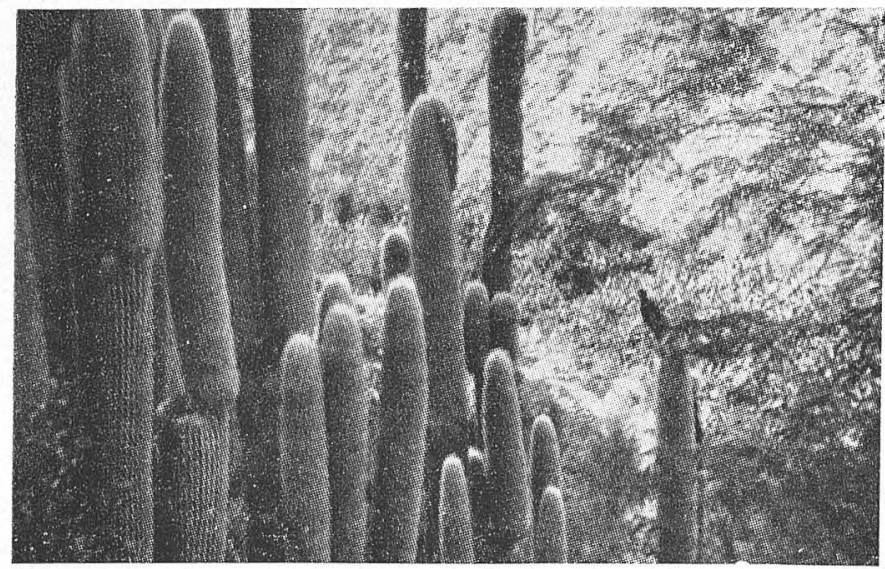

Después de algunas investigaciones, con la ayuda del Dr. Miranda, llegué a la conclusión de que se trata de la Hoverdenia speciosa. Esta planta se encontró una sola vez a principios del siglo pasado por un colector llamado Moritz en el Caracol de Atotonicapa, localidad muy vaga que no he podido identificar. Parece que no existe más que un solo ejemplar en el herbario de Berlín, Alemania. Fué descrita por Nees por la primera vez. En el Genera Plantarum de Bentham y Hooker después de la descripción de la planta, hay una nota que dice que esta planta tal vez procede de Colombia. Debido a esta confusión probablemente Standley no menciona la Hoverdenia en su tratado de Arboles y Arbustos de 
México. Es de suponerse que esta planta no figura en los herbarios de los Estados Unidos. De modo que se trata de un género con una sola especie, poco conocido y encontrado una sola vez. Su nombre vulgar es "olote."

Continuando la descripción de las especies vegetales halladas por mí en la barranca, mencionaré la gran cantidad de una Montanoa arbustiva de unos $5 \mathrm{~m}$. de altura. Como plantas trepadoras mencionaré la Porana probablemente la velutina y un Stigmaphyllum.

Las plantas herbáceas son casi las mismas que en las laderas. Hay Salvia, Hibanthus trichodonta, Perezia, Wissadula, Walteria, Stachytarpheta, Ruellia, Eucnide parviflora, Calophanes, Ageratum, etc.

Después de recorrer unos $15 \mathrm{Km}$. en la angosta y profunda Barranca de Tolantongo iniciamos la subida en un punto llamado Chalmita. En la ladera del cerro que escalamos la vegetación se cambia radicalmente. Estamos cerca de la laguna de Metztitlán. La vegetación se caracteriza por la enorme cantidad de un arbusto llamado Helietta parvifolia de la familia de las Rutáceas. El vulgo llama a este arbusto "guayacán" en toda la región. "浔s esta un arbusto de unos 2 a $4 \mathrm{~m}$. de altura con las hojas compuestas verdoso amarillentas. Las flores son pequeñas, de color blanco. Encontré una bellísima Fouquieria. Esta Fouquieria tiene las flores blancas y las hojas obovadas, de color verde y rojo. Standley no menciona esta especie de Fouquieria. No es imposible que se trate de una nueva especie.

Encontré gran cantidad de Hechtia, Agave, y diversas especies de Mammillarias.

(En las vistas tomadas en la Barranca de Tolantongo, pueden apreciarse hermosos ejemplares de Cephalocereus senilis). 